\title{
Pharmacodynamics Interaction of Quercetin and Captoprill on Doxorubicin Induced Myocardial Toxic Rats
}

\author{
Sengottuvel Thangavel 1,*iD , Gopalasatheeskumar Kasiramar ${ }^{2}$ (D), Sundaramoorthi Chenniappan ${ }^{3}$ (D) \\ 1 Department of Pharmacology, KMCH College of Pharmacy, Coimbatore-641048, The Tamil Nadu Dr. M.G.R. Medical \\ University, Tamil Nadu, India.; velvamsi@gmail.com (S.T.); \\ 2 Department of Pharmacy, Annamalai University, Annamalai Nagar, Chidambaram- 608002, Tamil Nadu, India; \\ gskpungai@gmail.com (G.K.); \\ 3 Department of Pharmaceutical Biotechnology, KMCH College of Pharmacy, Coimbatore-641048, The Tamil Nadu Dr. \\ M.G.R. Medical University, Tamil Nadu, India.; csundaramoorthi78@gmail.com (S.C.); \\ * Correspondence: velvamsi@gmail.com (S.T.);
}

Scopus Author ID 54685153500

Received: 5.06.2021; Revised: 9.07.2021; Accepted: 15.07.2021; Published: 8.08.2021

\begin{abstract}
Captopril (CAP), an ACE inhibitor, is widely used in the therapy of cardiovascular disease. Quercetin (QUE), a plant-derived flavonol that exerts cardioprotective activity through its antioxidant mechanism. A combination of CAP and QUE may produce synergistic or antagonistic cardioprotective effects. Therefore, the present study was designed to evaluate the pharmacodynamics interaction of QUE and CAP in Doxorubicin (Dox) induced oxidative myocardial damage in rats. Rats were pretreated with normal saline, QUE $(10 \mathrm{mg} / \mathrm{kg})$, and CAP $(30 \mathrm{mg} / \mathrm{kg})$ alone and in combination orally for 14 days. On the 14th day of treatment, rats were injected with Dox $(10 \mathrm{mg} / \mathrm{kg}$ single dose i.p) for the induction of myocardial damage. There was a substantial fall and rise in activities of marker enzymes such as CKMB, LDH, AST, and ALT in serum and elevation of ST-segment, increased QT interval, and HR upon Dox administration. Pretreatment with QUE and CAP alone significantly restored the above parameters. But, the Concomitant pretreatment with QUE and CAP was found to be less significantly restored the Dox-induced alterations. The present study suggests that concomitant pretreatment with CAP and QUE could attenuate cardiovascular protection than that of alone pretreatment. It may be due to the antagonistic effect between the two drugs.
\end{abstract}

Keywords: cardioprotective; herb-drug interaction; antagonistic effect; CK-MB; LDH.

(C) 2021 by the authors. This article is an open-access article distributed under the terms and conditions of the Creative Commons Attribution (CC BY) license (https://creativecommons.org/licenses/by/4.0/).

\section{Introduction}

Cardiovascular diseases, particularly myocardial toxicity, are one of the leading causes of mortality. Cardiovascular disease risk factors are hypertension, atherosclerosis, drugs like doxorubicin (Dox) \& catecholamines like isoproterenol, isoprenaline, etc. Ischemia, reperfusion of coronary blood flow following ischemia, has deleterious consequences on cardiac function and may lead to an extension of myocardial tissue injury due to accumulation of free radicals after reperfusion [1-3].

The synthetic drugs used to treat myocardial toxicity are "ACE inhibitors like Captopril (CAP), $\beta$-blockers like Propranolol, statins like Simvastatin, Atorvastatin" etc. Apart from the therapeutic effects, these drugs also possess many side effects like "dry persistent cough, blurred vision, headache, liver damage, fatigue" etc., which are less seen with the use of herbal drugs, hence the use of herbal supplements have become increasingly popular in recent years $[4,5]$. The renin-angiotensin-aldosterone system is a major endocrine/paracrine system 
involved in regulating a myriad of cardiovascular processes. Its role in the pathogenesis of hypertension, cardiac hypertrophy, and atherosclerosis is well established. Because angiotensin-converting enzyme inhibitors (ACE-I) such as CAP, lisinopril, enalapril etc., exhibit cardioprotective, vasculoprotective, antiatherogenic effects and contribute to tissue protection, they are widely used in the therapy of cardiovascular disease [6].

Flavonoids belong to the large and heterogenic group of plant polyphenols marketed for various health effects in complementary or alternative medical therapies. Due to their widespread occurrence in fruits and vegetables, flavonoids are regularly ingested by humans together with plants and the plant-derived from foods and beverages [7, 8]. Quercetin (QUE) is the most abundant of plant-derived flavonoid molecules. Flavonoids, as a rule, are antioxidants and a number of QUE's effects are due to its antioxidant activity [9- 11]. The cardiovascular effects of QUE center on its antioxidant and anti-inflammatory ability to inhibit platelet aggregation ex vivo [12]. Simultaneous administration of herbal constituents \& drugs may mimic, magnify or oppose the pharmacological effects of each other; such rational use may be beneficial or harmful. It has been documented that many patients use herbal supplements concurrently with the prescribed conventional drugs [13, 14]. Simultaneous administration of herbs and drugs may show some interactions on pharmacological effects of each other [15].

In literature, QUE and Sitagliptin combination [16], QUE and $\alpha$-tocopherol combination [17], QUE and Rutin combination [18], QUE and losartan combination [19] and CAP and L-arginine combination [20] have been reported for its pharmacodynamics and cardioprotective activity. However, there is no pharmacodynamics study on QUE-CAP combination. Therefore, the current research was aimed to evaluate the possible pharmacodynamic interactions of flavonoid QUE with CAP in rats subjected to Dox-induced myocardial damage.

\section{Materials and Methods}

\subsection{Materials and methods.}

CAP was a generous gift from Changzhou Pharmaceutical Factory, India. QUE was procured from Sigma-Aldrich (USA), Bangalore. Dox hydrochloride was used in the form of an injectable commercial product (ADRIM, mfg. by Freseriuskabi, Dabur). Ellman's reagent Sigma-Aldrich (USA), Thiobarbituric acid Himedia Ltd., Mumbai, Trichloroacetic acid Himedia Ltd., Mumbai, Other chemicals required were purchased from Himedia (India).

\subsection{Experimental animals.}

The complete course of the experiment was carried out using healthy male Wistar rats weighing between 150-200 g, which were procured from Sri Venkateswara Enterprises, Bangalore. They were housed in standard laboratory conditions at room temperature and $12 \mathrm{~h}$ light/dark cycle [21]. The animals were provided with a standard pelleted diet obtained commercially from the manufacturer (Amrut Laboratories, Sangli) and water ad libitum. After seven days of acclimatization period, they were randomly selected for different experimental groups. Ethical clearance was obtained from Institutional Animal Ethics Committee (IAEC Reg. No.: 221/CPCSEA) KLEU's College Of Pharmacy, Belgaum, before experimenting. 


\subsection{Dose selection.}

The human dose of CAP $150 \mathrm{mg} / \mathrm{kg}$ was converted into an animal dose $30 \mathrm{mg} / \mathrm{kg}$ respectively and administered as a single dose orally for 7 days [22]. QUE at $10 \mathrm{mg} / \mathrm{kg}$ was weighed, and the residue was dissolved in normal saline and administered orally for 14 days.

\subsection{Experimental study design.}

The adult male Wistar rats were divided into six groups of six animals and received the following treatment.

Group I (Normal control): Received Normal saline ( $2 \mathrm{ml} / \mathrm{kg}$, p.o.).

Group II (Dox treated): Received Normal saline $+10 \mathrm{mg} / \mathrm{kg}$, i.p of Dox on $14^{\text {th }}$ day.

Group III (QUE treated): Received $10 \mathrm{mg} / \mathrm{kg}$, p.o, of QUE for 14 days $+10 \mathrm{mg} / \mathrm{kg}$, i.p of Dox at $14^{\text {th }}$ day.

Group IV (CAP treated): Received $30 \mathrm{mg} / \mathrm{kg}$ p.o, of CAP $+10 \mathrm{mg} / \mathrm{kg}$, i.p of Dox at $14^{\text {th }}$ day.

Group V (CAP-QUE treated-I): Received $30 \mathrm{mg} / \mathrm{kg}$ p.o, of CAP and $10 \mathrm{mg} / \mathrm{kg}$, p.o, of QUE for 14 days $+10 \mathrm{mg} / \mathrm{kg}$, i.p of Dox at $14^{\text {th }}$ day.

Group VI (combination treated-II): Received $30 \mathrm{mg} / \mathrm{kg}$ p.o, of CAP, and $10 \mathrm{mg} / \mathrm{kg}$, p.o, of QUE for 14 days.

At the end of the treatment period, animals of all the groups excluding group-I and group VI were administered with Dox $(10 \mathrm{mg} / \mathrm{kg}$, single dose i.p) to induce myocardial toxicity $[23,24,25]$. After $72 \mathrm{~h}$ induction of myocardial toxicity, the ECGs of the rats were recorded, and animals were sacrificed. Blood was collected, and the serum was separated by cold centrifugation (at $3000 \mathrm{rpm}$ for 10 minutes) for biochemical estimation. And also, Bodyweight, Heart weight, liver weight was analyzed [26].

\subsection{Measurement of serum biomarker enzymes.}

The serum was used for estimation of cardiac marker enzymes such as Alanine transaminase (ALT), Aspartate transaminase (AST), Lactate dehydrogenase (LDH), Creatine kinase-MB fraction (CK-MB), Alkaline phosphatase (ALP) were analyzed using commercially available diagnostic kits (Coral Clinical Systems, Goa) and troponin I (Peerless Biotech Pvt.Ltd).

\subsection{Measurement of serum lipid profile.}

Total Cholesterol (TC), Triglyceride (TG) and High-Density Lipoprotein (HDL), were measured by using ERBA Diagnostic Kits. Low-Density Lipoprotein (LDL) was measured by using the Friedewald formula [27, 28].

\subsection{Recording of ECG parameters.}

At the end of the experimental period, the animals were anesthetized using pentobarbital sodium 35mg/kg i.p. The Lead II ECGs of all animals were recorded using Biopac Student Lab PRO 3.7 software (Model No. MP35) make BIOPAC Systems, Inc. Aero Camino, Goleta, CA 93117. The ECG parameters measured are QRS complex (in seconds), QT interval (in seconds), Heart rate (BPM). 


\subsection{Statistical analysis.}

Values were expressed as Mean \pm Standard Error Mean (SEM). The data were analyzed by one-way ANOVA followed by Tukey Multiple Comparison Test. $\mathrm{P}<0.01$ was considered significant.

\section{Results and Discussion}

\subsection{Effect on bodyweight, heart weight, liver weight.}

The results of the effect of various treatments on rats' body weight, heart weight, liver weight, and the ratio of heart to body weight in Dox-induced myocardial toxicity are shown in Table 1.

Table 1. Effect of various treatments on rats Bodyweight, Heart weight, liver weight and the ratio of Heart to Bodyweight in Doxorubicin-induced myocardial toxicity

\begin{tabular}{l|l|l|l|l|l} 
Groups & $\begin{array}{l}\text { Initial body } \\
\text { weight }(\mathbf{g})\end{array}$ & $\begin{array}{l}\text { Final body } \\
\text { weight }(\mathbf{g})\end{array}$ & $\begin{array}{l}\text { Heart weight } \\
(\mathbf{g})\end{array}$ & $\begin{array}{l}\text { Liver weight } \\
(\mathbf{g})\end{array}$ & $\begin{array}{l}\text { Heart/body } \\
\text { weight Ratio } \\
\left(\times \mathbf{1 0}^{-3}\right)\end{array}$ \\
\hline Normal & $135.0 \pm 1.612$ & $150.0 \pm 3.421$ & $0.540 \pm 4.341$ & $5.401 \pm 0.261$ & $3.6 \pm 0.106$ \\
\hline Dox & $159.2 \pm 6.754^{\#}$ & $133.4 \pm 6.735^{\#}$ & $0.513 \pm 21.22^{\mathrm{ns}}$ & $5.262 \pm 0.431^{\mathrm{ns}}$ & $3.4 \pm 0.093^{\mathrm{ns}}$ \\
\hline QUE + Dox & $158.0 \pm 2.280$ & $143.2 \pm 7.664^{\mathrm{ns}}$ & $0.535 \pm 36.79^{\mathrm{ns}}$ & $5.022 \pm 0.379^{\mathrm{ns}}$ & $3.6 \pm 0.180^{\mathrm{ns}}$ \\
\hline CAP + Dox & $164.6 \pm 8.232$ & $190.2 \pm 11.36^{* * *}$ & $0.684 \pm 23.54^{*}$ & $6.278 \pm 0.190^{\mathrm{ns}}$ & $3.8 \pm 0.24^{\mathrm{ns}}$ \\
\hline $\begin{array}{l}\text { QUE+CAP } \\
+ \text { Dox }\end{array}$ & $170.4 \pm 4.833$ & $174.2 \pm 2.354^{*}$ & $0.594 \pm 40.71^{\mathrm{ns}}$ & $6.399 \pm 0.425^{\mathrm{ns}}$ & $3.4 \pm 0.24^{\mathrm{ns}}$ \\
\hline $\begin{array}{l}\text { QUE }+ \\
\text { CAP }\end{array}$ & $163.0 \pm 4.195$ & $188.0 \pm 11.31^{* * *}$ & $0.750 \pm 60.02^{*}$ & $7.861 \pm 0.755^{* *}$ & $3.9 \pm 0.19^{\mathrm{ns}}$
\end{tabular}

Bodyweight was measured on $0^{\text {th }}$ day and $3^{\text {rd }}$ day of Doxorubicin treatment, and Heart, Liver weight was measured at $3^{\text {rd }}$ day of Doxorubicin treatment. N=6; Values are expressed as mean \pm SEM; Compared with Normal: \# $\mathrm{P}<0.1$, \# \# $\mathrm{P}<0.01$, \# \# \# $\mathrm{P}<0.001$. Compared with Doxorubicin: $* \mathrm{P}<0.1, * * \mathrm{P}<0.01, * * * \mathrm{P}<0.001, \mathrm{~ns}=$ non significant. One-way ANOVA followed by Turkey test.

The bodyweight of Dox-treated rats was significantly reduced $(133.4 \pm 6.35 \mathrm{~g}, \mathrm{p}<0.01)$ compared to that of normal rats $(150.0 \pm 3.45 \mathrm{~g})$. The rats pretreated with CAP $30 \mathrm{mg} / \mathrm{kg}$, p.o and QUE 10mg/kg, p.o followed by Dox administration showed a significant increase in body weight compared with Dox-treated rats. The heart weight of Dox-treated rats was significantly decreased $(0.513 .8 \pm 0.21 \mathrm{~g}, \mathrm{p}<0.001)$ compared to that of normal rats $(0.540 \pm 0.434 \mathrm{~g})$. The rats pretreated with CAP $(30 \mathrm{mg} / \mathrm{kg}, \mathrm{p} . \mathrm{o})$ and QUE $(10 \mathrm{mg} / \mathrm{kg}$, p.o) showed no significant increase $(0.684 \pm 0.23 .54,0.535 \pm 0.367 \mathrm{~g}$ respectively $)$ in heart weight as compared to that of Dox treated rats in heart weight when compared with Dox treated group. The liver weight of Dox-treated rats $(5.26 \pm 0.43 \mathrm{~g})$ showed no significant changes compared with normal rats $(5.401 \pm 0.261 \mathrm{~g})$. The rats pretreated with CAP and QUE alone and in combination showed no significant changes in liver weight compared with Dox-treated rats. The Heart to Bodyweight ratio of Dox-treated rats was significantly decreased $(3.4 \times 10-3, \mathrm{p}<0.01)$ compared with normal rats. The rats pretreated with CAP (30mg/kg, p.o) and QUE (10mg/kg, p.o) alone showed a significant increase in heart-to-body weight ratio compared to Dox treated rats. The rats pretreated with CAP (30mg/kg, p.o) + QUE (10mg/kg, p.o) followed by Dox administration showed no significant changes in heart to body weight ratio compared with Dox treated groups.

\subsection{Effect on serum biomarker enzymes.}

The results of the effect of various treatments on rat serum biomarker enzymes in Doxinduced myocardial toxicity are shown in Figure 1. 

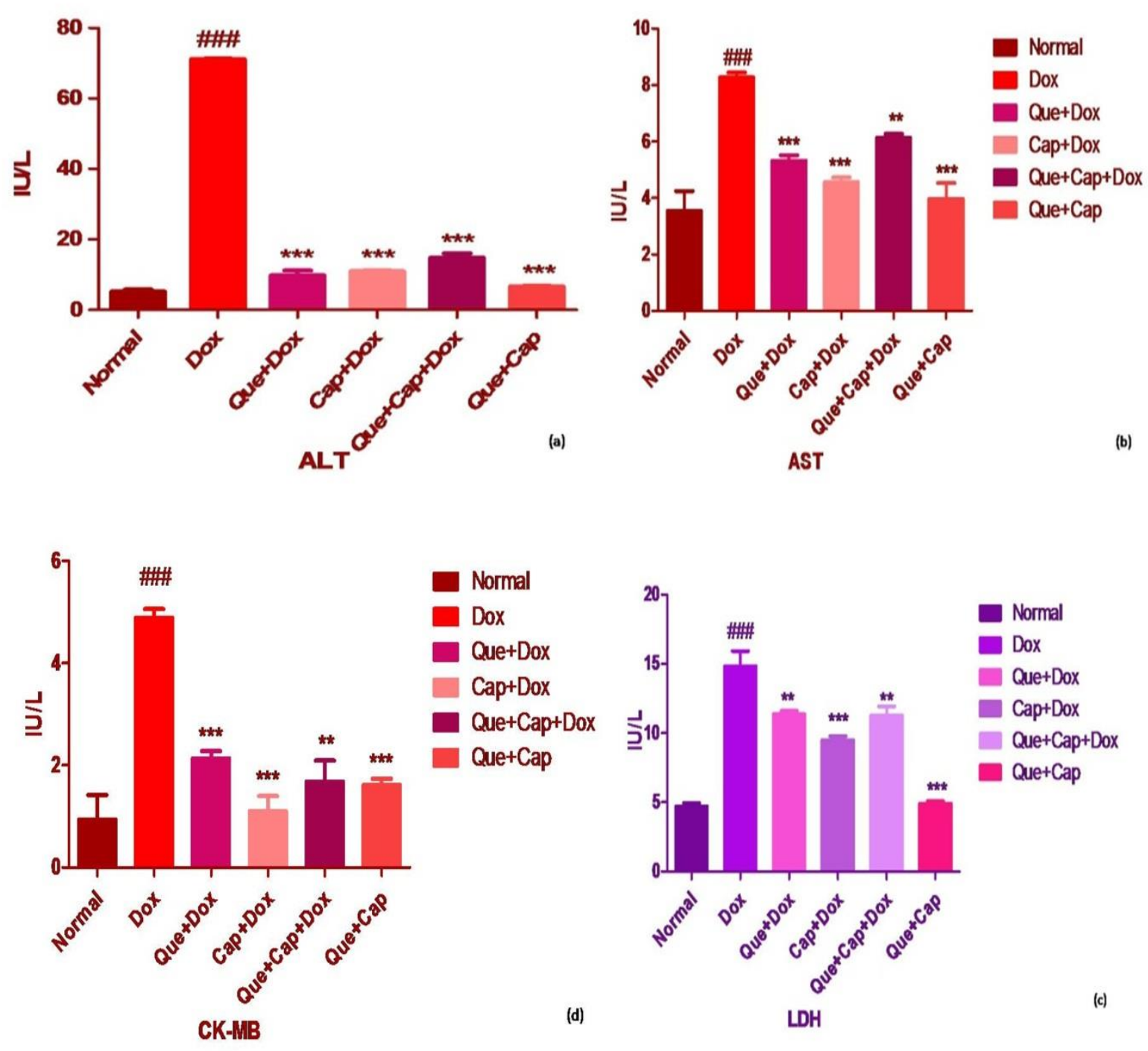

Figure 1. Effect of various treatments on rat serum biomarker enzymes in Doxorubicin induced myocardial toxicity. (a) ALT (b) AST (c) LDH (d) CK-MB; N=6; Values are expressed as mean \pm SEM; Compared with Normal: \# $\mathrm{P}<0.1$, \# \# $\mathrm{P}<0.01$, \# \# \# $\mathrm{P}<0.001$. Compared with Dox: $* \mathrm{P}<0.1$, ** $\mathrm{P}<0.01$, *** $\mathrm{P}<0.001$, ns $=$ nonsignificant. One way ANOVA followed by Turkey test.

Acute administration of Dox showed a significant increase in the levels of serum cardio biomarker enzymes viz. LDH, CKMB, ALT, and AST when compared to normal rats $(\mathrm{P}<$ 0.001). The increased concentration of serum enzymes is a well-accepted quantitative index of myocardial damage caused by Dox treatment. Pretreatment with CAP (30 mg/kg, p.o), QUE $(10 \mathrm{mg} / \mathrm{kg}, \mathrm{p} . \mathrm{o})$ alone significantly $(\mathrm{P}<0.001)$ reduced the elevated serum enzyme levels in Dox-induced cardiotoxic rats when compared to Dox treated rats. Whereas concomitant pretreatment with CAP and QUE (30mg/kg, p.o and $10 \mathrm{mg} / \mathrm{kg}$, p.o) significantly restored $(\mathrm{p}<0.01)$ the activities of these enzymes in Dox-induced cardiotoxic rats. The Dox-treated rats showed the presence of Troponin I, while the normal group rats showed the absence of Troponin I in serum. The rats pretreated with CAP (30mg/kg, p.o), QUE (10mg/kg, p.o), and both combination groups showed the absence of Troponin-I in serum.

\subsection{Effect on serum lipid profile.}

The results of the effect of various treatments on rat serum lipid parameters in Doxinduced myocardial toxicity are shown in Figure 2. 


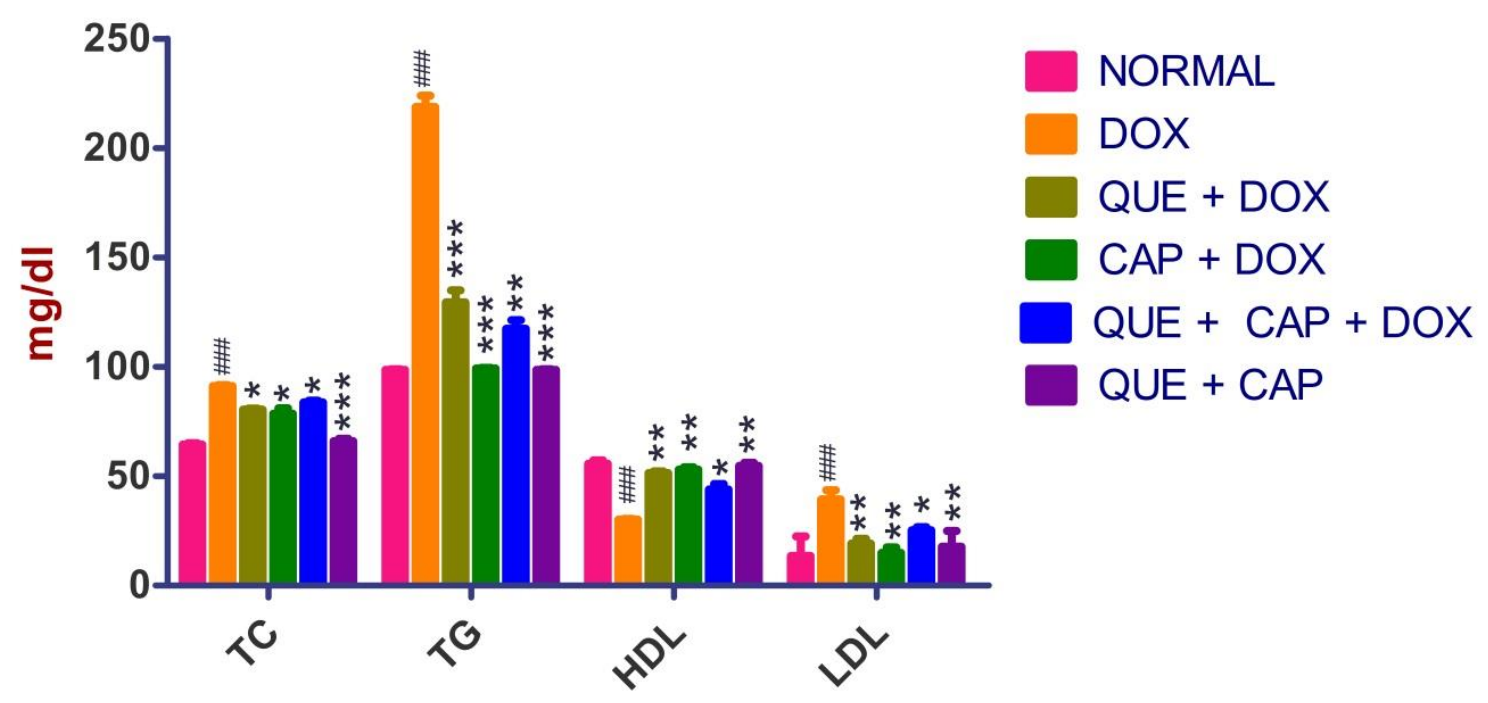

Figure 2. Effect of various treatments on rats' serum lipid profile (TC,TG, HDL\&LDL) in Doxorubicin-induced myocardial toxicity. $\mathrm{N}=6$; Values are expressed as mean $\pm \mathrm{SEM}$; Compared with Normal control: \# $\mathrm{P}<0.1$, \# \# $\mathrm{P}<0.01$, \# \# \# $\mathrm{P}<0.001$. Compared with Disease control: $* \mathrm{P}<0.1, * * \mathrm{P}<0.01$, $* * * \mathrm{P}<0.001$, ns $=$ non-significant. One-way ANOVA followed by Turkey test.

The Dox-treated group showed a significant increase $(\mathrm{P}<0.001)$ in the levels of $\mathrm{TC}, \mathrm{TG}$, and LDL compared to the normal group. Pretreatment with CAP (30 mg/kg, p.o), QUE (30 $\mathrm{mg} / \mathrm{kg}, \mathrm{p} . \mathrm{o})$ alone significantly $(\mathrm{P}<0.001)$ decreased the elevated lipid levels when compared to Dox treated rats. Whereas concomitant pretreatment with CAP and QUE (CAP 30mg/kg, p.o + QUE 10mg/kg p.o) significantly $(\mathrm{p}<0.01)$ decreased the elevated lipid levels in Doxinduced cardiotoxic rats. Animals treated with Dox showed a significant $(\mathrm{P}<0.01)$ decrease in HDL level compared to the normal group. Pretreatment with CAP (30 mg/kg, p.o), QUE (10 $\mathrm{mg} / \mathrm{kg}, \mathrm{p} . \mathrm{o})$ alone showed a significant $(\mathrm{p}<0.01)$ increase in HDL level when compared to Doxtreated rats. Whereas concomitant pretreatment with CAP and QUE $(30 \mathrm{mg} / \mathrm{kg}, \mathrm{p} .0+10 \mathrm{mg} / \mathrm{kg}$, p.o) significantly increased $(\mathrm{P}<0.1)$ the HDL level as compared to Dox treated rats. Hence CAP and QUE combined pretreatment significantly restored the serum lipid levels in Dox-induced cardiotoxic rats but showed a lesser effect when compared to individual treatments.

\subsection{Effect on ECG parameters.}

The results of the effect of various treatments on ECG parameters in Dox-induced myocardial toxicity are shown in Table 2. The Dox-treated group showed significant changes in the repolarization phase of the ECG: Significant prolongation of QT interval and elevation of ST-segment, with no significant effect on QRS complex, compared to the normal group. In addition, a significant $(\mathrm{P}<0.001)$ increase in Dox-treated rats' heart rate was observed compared to the normal group. Pretreatment with QUE $10 \mathrm{mg} / \mathrm{kg}$, p.o and CAP $30 \mathrm{mg} / \mathrm{kg}$, p.o alone significantly reduced the ECG alterations when compared to Dox treated group. Concomitant pretreatment with QUE $10 \mathrm{mg} / \mathrm{kg}$, p.o and CAP $30 \mathrm{mg} / \mathrm{kg}$, p.o significantly normalized these changes compared to Dox-induced cardiotoxic rats but showed a lesser effect when compared to individual treatments.

Table 2. Effect of various treatments on ECG parameters.

\begin{tabular}{l|l|l|l} 
Groups & Heart rate $(\mathbf{b p m})$ & QRS complex $(\mathbf{s e c})$ & QT interval $(\mathbf{s e c})$ \\
\hline Normal & $384.3 \pm 15.71$ & $0.050 \pm 0.0012$ & $0.090 \pm 0.0015$ \\
\hline Dox & $521.7 \pm 14.97^{\# \# \#}$ & $0.038 \pm 0.0028^{\# \# \#}$ & $0.90 \pm 0.0012^{\# \# \#}$
\end{tabular}




\begin{tabular}{l|l|l|l} 
Groups & Heart rate (bpm) & QRS complex (sec) & QT interval (sec) \\
\hline QUE + Dox & $461.3 \pm 15.71^{* * *}$ & $0.040 \pm 0.0012^{*}$ & $0.085 \pm 0.0015^{* * * *}$ \\
\hline CAP + Dox & $428 \pm 16.40^{* * * *}$ & $0.040 \pm 0.0028^{*}$ & $0.090 \pm 0.0015^{* * *}$ \\
\hline QUE + CAP +Dox & $474 \pm 15.41^{* * * *}$ & $0.055 \pm 0.0021^{*}$ & $0.120 \pm 0.00015^{* *}$ \\
\hline QUE + CAP & $413.2 \pm 16.03^{* * *}$ & $0.050 \pm 0.0028^{*}$ & $0.095 \pm 0.0015^{* * *}$
\end{tabular}

ECG parameters were measured on $3^{\text {rd }}$ day of Doxorubicin treatment. $\mathrm{N}=6$; Values are expressed as mean $\pm \mathrm{SEM}$; Compared with Normal: \# $\mathrm{P}<0.1$, \# \# $\mathrm{P}<0.01$, \# \# \# $\mathrm{P}<0.001$. Compared with Doxorubicin: * $\mathrm{P}<0.1$, $* * \mathrm{P}<0.01, * * * \mathrm{P}<0.001$, ns $=$ non significant. One-way ANOVA followed by Turkey test.

An herb-drug interaction is defined as any pharmacological modification caused by an herbal substance(s) to another exogenous chemical (e.g., a prescription medication) in the diagnostic, therapeutic, or other action of a drug in or on the body [29-31]. An herb can potentially mimic, increase, or decrease the activities of co-administered medicines, and the significances of these connections can be favorable, unwanted, or injurious effects [32, 33]. It's worth noting that the herbal mixture's putative active ingredient(s) and other ingredients could potentially interact with a variety of drug classes. [34-36]. The interface among herbs and medicines might increase or reduce the pharmacological properties of any component. Synergistic and beneficial properties may confuse the dosing of long-run medicines. E.g., herbals traditionally used to reduce glucose levels in diabetes mellitus could therapeutically induce hypoglycemia if combined with conventional drugs [37]. Herb-drug interactions are possible in the following scenarios: When warfarin is taken with Ginkgo biloba, Salvia miltiorrhiza, and Allium sativum, it can cause bleeding. And digoxin, theophylline, and cyclosporine bioavailability are all reduced when coupled with Hypericumper foratum, etc. [38]. The Theophylline was taken along with Capsicum spp (chilli pepper), which can increase absorption and bioavailability. Health-care practitioners should care for the patients against mixing herbs and pharmaceutical drugs. The current study reported the pharmacodynamics interaction between synthetic drugs (CAP) and natural drugs (QUE). Dox is a powerful, wellknown, and very effective medicine used to treat various cancers, including solid tumors, leukemia, soft tissue sarcoma, breast cancer, lung cancer, and esophageal carcinomas. Its clinical efficacy is still restricted due to its particular cardiac tissue toxicity [39, 40]. After cumulative Dox treatment, congestive heart failure, cardiomyopathy, and electrocardiographic abnormalities were seen $[41,42]$. There was a substantial rise in the activities of marker enzymes such as CK-MB, LDH, AST, and ALT in serum of Dox-treated rats.

Further elevation of ST-segment, increased QT interval, and HR were also observed in Dox-treated cardiotoxic rats. Pretreatment with QUE and CAP alone significantly $(\mathrm{p}<0.001)$ restored the above parameters. But, the Concomitant pretreatment with QUE and CAP was found to be less significantly $(\mathrm{p}<0.01)$ restored the DOX-induced alterations in cardiotoxic rats.

\section{Conclusions}

In conclusion, present results suggest that concomitant pretreatment with CAP and QUE could attenuate cardiovascular protection than that of alone pretreatment. It may be due to the antagonistic effect between the two drugs in Dox-induced cardiotoxic rats. Further studies, i.e., pharmacokinetic studies, are needed to prove the antagonistic interaction between CAP and QUE in Dox-induced cardiotoxic rats.

\section{Funding}

This research received no external funding. 


\section{Acknowledgments}

This research has no acknowledgment.

\section{Conflicts of Interest}

The authors declare no conflict of interest.

\section{References}

1. Mohanty, I; Gupta, S.K.; Talwar, K.K.; Dinda, A; Joshi, S; Bansal, P; Saxena, A.; Singh Arya, D. Cardioprotection from ischemia and reperfusion injury by Withania somnifera: A hemodynamic, biochemical and histopatholpgical assessment. Mol Cell Biochem 2004, 260, 39-47, https://doi.org/10.1023/b:mcbi.0000026051.16803.03.

2. Khan, M.A.B.; Hashim, M.J.; Mustafa, H.; Baniyas, M.Y.; Al Suwaidi, S.K.B.M.; AlKatheeri, R.; Alblooshi, F.M.K.; Almatrooshi, M.E.A.H.; Alzaabi, M.E.H.; Al Darmaki, R.S. Global epidemiology of ischemic heart disease: Results from the global burden of disease study. Cureus 2020, 12, 9349, https://doi.org/10.7759/cureus.9349.

3. Pengpid, S.; Peltzer, K. Prevalence and Correlates of Self-Reported Cardiovascular Diseases Among a Nationally Representative Population-Based Sample of Adults in Ecuador in 2018. Vasc Health Risk Manag 2021, 17, 195-202, https://doi.org/10.2147/VHRM.S299272.

4. Asdaq, S.M.B.; Inamdar, M.N. Pharmacodynamic interaction of garlic with hydrochlorothiazide in rats. Indian J Physiol Pharmacol 2009, 53, 127-136.

5. Trapani, D.; Zagami, P.; Nicolo, E.; Pravettoni, G.; Curigliano, G. Management of Cardiac Toxicity Induced by Chemotherapy. J Clin Med 2020, 9, 2885, https://doi.org/10.3390/jcm9092885.

6. Kojic, Z.; Gopcevic, K.; Marinkovic, D.; Tasic, D. Effect of captopril on serum lipid levels and cardiac mitochondrial oxygen consumption in experimentally-induced hypercholesterolemia in rabbits. Physiol res 2011, 60, 177-184, https://doi.org/10.33549/physiolres.932177.

7. Rainer, C.; Silvia, W.; Siegfried, W.; Langguthc, P. Effects of the flavonol quercetin on the bioavailability of simvastatin in pigs. Eur J Pharm Sci 2009, 38, 519-524, https://doi.org/10.1016/j.ejps.2009.09.018.

8. Xing, C.; Tian, Z., Wenjin Z.; Zhenyu Z.; Jiahui S. Natural Drugs as a Treatment Strategy for Cardiovascular Disease through the Regulation of Oxidative Stress. Oxid Med Cell Longev 2020, 1-20, https://doi.org/10.1155/2020/5430407.

9. Gopalasatheeskumar, K.; Ariharasivakumar, G.; Sengottuvel, T.; Sanish Devan, V.; Srividhya, V. Quantification of Total Phenolic and Flavonoid content in leaves of Cucumis melo var agrestis using UVspectrophotometer. Asian $J$ Research Chem 2019, 12, 335-337, https://doi.org/10.5958/09744150.2019.00062.2.

10. Qiang, Z.; Wenbo, Y.; Jiechao, L.; Hui, L.; Zhenzhen, L.; Chunling, Z.; Dalei, C.; Zhonggao, J. Identification of Six Flavonoids as Novel Cellular Antioxidants and Their Structure-Activity Relationship. Oxid Med Cell Longev 2020, 4150897, 12, https://doi.org/10.1155/2020/4150897.

11. Ullah, A.; Munir, S.; Badshah, S.L.; Khan, N.; Ghani, L.; Poulson, B.G.; Emwas, A.-H.; Jaremko, M. Important Flavonoids and Their Role as a Therapeutic Agent. Molecules 2020, 25, 5243, https://doi.org/10.3390/molecules25225243.

12. Hubbard, G.P.; Wolffram, S.; Lovegrove, J.A.; Gibbins, J.M. The role of polyphenolic compounds in the diet as inhibitors of platelet function. Proc Nutr Soc 2003, 62(2), 469-478, https://doi.org/10.1079/pns2003253.

13. Abebe, W. Herbal medications: Potential for adverse interactions with analgesic drugs. J Clin Pharm Ther 2002, 27, 391-401, https://doi.org/10.1046/j.1365-2710.2002.00444.x.

14. Azizah, N.; Halimah, E.; Puspitasari, I.M.; Hasanah, A.N. Simultaneous Use of Herbal Medicines and Antihypertensive Drugs Among Hypertensive Patients in the Community: A Review. J Multidiscip Healthc 2021, 14, 259-270, https://doi.org/10.2147/JMDH.S289156.

15. Erhirhie, E.O.; Ikegbune, C.; Okeke, A.I.; Onwuzuligbo, C.C.; Madubuogwu, N.U.; Chukwudulue, U.M.; Okonkwo, O.B. Antimalarial herbal drugs: a review of their interactions with conventional antimalarial drugs. Clinical Phytoscience 2021, 7, 4, https://doi.org/10.1186/s40816-020-00242-4.

16. Aziz, T.A. Cardioprotective Effect of Quercetin and Sitagliptin in Doxorubicin-Induced Cardiac Toxicity in Rats. Cancer Manag Res 2021, 13, 2349-2357, https://doi.org/10.2147/CMAR.S300495.

17. Punithavathi, V.R.; Stanely, M.P.P. The cardioprotective effects of a combination of quercetin and $\alpha$ tocopherol on isoproterenol-induced myocardial infarcted rats. J Biochem Mol Toxicol 2011, 25, 28-40, https://doi.org/10.1002/jbt.20357. 
18. Mahmoud, H.U.R.; Ahmed, O.M.; Fahim, H.I.; Ahmed, N.A.; Ashour, M.B. Effects of rutin and quercetin on doxorubicin-induced renocardiotoxicity in male wistar rats. Adv Anim Vet Sci 2020, 8, 370-384, http://doi.org/10.17582/journal.aavs/2020/8.4.370.384.

19. Matouk, A.I.; Taye, A.; Heeba, G.H.; El-Moselhy, M.A. Quercetin augments the protective effect of losartan against chronic doxorubicin cardiotoxicity in rats. Environ Toxicol Pharmacol 2013, 36, 443-450, http://doi.org/10.1016/j.etap.2013.05.006.

20. Greenberg, S.; Chernin, G.; Shapira, I.; George, J.; Wollman, Y.; Laniado, S.; Keren, G. Captopril and Larginine have a synergistic cardioprotective effect in ischemic-reperfusion injury in the isolated rat heart. $J$ Cardiovasc Pharmacol Ther 2000, 5, 281-90, http://doi.org/10.1054/JCPT.2000.18021.

21. Gopalasatheeskumar, K.; Ariharasivakumar, G.; Kalaichelvan, V.K.; Sengottuvel, T.; Sanish Devan, V.; Srividhya, V. Antihyperglycemic and antihyperlipidemic activities of wild musk melon (Cucumis melo var. agrestis) in streptozotocin-nicotinamide induced diabetic rats. Chin Herb Med 2020, 12, 399-405, https://doi.org/10.1016/j.chmed.2020.02.005.

22. Ghosh, M.N. Fundamentals of experimental pharmacology, 6th ed., Hilton \& Co, 2008.

23. Sergazy, S.; Shulgau, Z.; Fedotovskikh, G.; Chulenbayeva, L.; Nurgozhina, A.; Nurgaziyev, M.; Krivyh, E.; Kamyshanskiy, Y.; Kushugulova, A.; Gulyayev, A.; Aljofan, M. Cardioprotective effect of grape polyphenol extract against doxorubicin induced cardiotoxicity. Sci. Rep. 2020, 10, 14720, https://doi.org/10.1038/s41598-020-71827-9.

24. Zhang, N.; Shou, B.; Chen, L.; Lai, X.; Luo, Y.; Meng, X.; Liu, R. Cardioprotective Effects of Latifolin Against Doxorubicin-Induced Cardiotoxicity by Macrophage Polarization in Mice. J. Cardiovasc. Pharmacol. 2020, 75, 564-572, https://doi.org/10.1097/FJC.0000000000000827.

25. Jayasinghe, A.N.S.; Ruwani, P.H.; Kamani A.P.W.J.; Lakmini K.B.M. Cardioprotective Potential of Murraya koenigii (L.) Spreng. Leaf Extract against Doxorubicin-Induced Cardiotoxicity in Rats. Evid Based Complement Alternat Med 2020, 6023737, 1, https://doi.org/10.1155/2020/6023737.

26. Nayagam, A.A.J.; Gunasekaran, S.; Rangarajan, S.; Muthaiah, S. Myocardial potency of Caesalpinia bonducella Linn. on doxorubicin induced myocardial infarction in albino rats. Clinical Phytoscience 2019, 5 , 43, https://doi.org/10.1186/s40816-019-0146-7.

27. Warnick, G.R.; Knopp, R.H.; Fitzpatrick, V.; Branson L. Estimating low-density lipoprotein cholesterol by the Friedewald equation is adequate for classifying patients on the basis of nationally recommended cutpoints. Clin Chem 1990, 36, 15-19.

28. Rajadurai, M.; Stanely, M.P. Preventive effect of naringin on cardiac markers,electrocardiographic patterns and lysosomal hydrolases in normal and isoproterenol-induced myocardial infarction in Wistar rats. Toxicol 2007, 230, 178-188, https://doi.org/10.1016/j.tox.2006.11.053.

29. Brazier, N.C., Levine, M.A. Drug-herb interaction among commonly used conventional medicines. A compendium for health care professionals. Am J Ther 2003, 10, 163-69, https://doi.org/10.1097/00045391200305000-00003.

30. Sharma, A.K.; Kapoor, V.K.; Kaur G. Herb-drug interactions: a mechanistic approach. Drug Chem Toxicol 2020, 12, 1-10, https://doi.org/10.1080/01480545.2020.1738454.

31. Auxtero, M.D.; Chalante, S.; Abade, M.R.; Jorge, R.; Fernandes, A.I. Potential Herb-Drug Interactions in the Management of Age-Related Cognitive Dysfunction. Pharmaceutics, 2021, 19, 124, https://doi.org/10.3390/pharmaceutics13010124.

32. Mohammadi, S.; Asghari, G.; Emami-Naini, A.; Mansourian, M.; Badri, S. Herbal supplement use and herbdrug interactions among patients with kidney disease. J Pharm Pract Res 2020, 9, 61-67, https://doi.org/10.4103/jrpp.JRPP_20_30.

33. Fugh-Berman, A.; Ernst, E. Herb-drug interactions: Review and assessment of report reliability. Br J Clin Pharmacol 2001, 52, 587-595, https://doi.org/10.1046/j.0306-5251.2001.01469.x.

34. Chi, D.; Ding, D.; Zhao, Q.; Liang, X.; Wu, W.; Luo, J.; Wang, B. Potential herb-drug interactions in community-dwelling older adults in China: the Shanghai Aging Study. Aging Clin. Exp. Res. 2020, 32, 26772685, https://doi.org/10.1007/s40520-020-01489-0.

35. Miller, L.G. Herbal medicinal selected clinical considerations focusing on known or potential drug-herb interactions. Arch Int Med 1998, 158, 2200-2211, https://doi.org/10.1001/archinte.158.20.2200.

36. Zhang, F.; Huang, J.; He, R.-J.; Wang, L.; Huo, P.-C.; Guan, X.-Q.; Fang, S.-Q.; Xiang, Y.-W.; Jia, S.-N.; Ge, G.-B. Herb-drug interaction between Styrax and warfarin: Molecular basis and mechanism. Phytomedicine 2020, 77, 153287, https://doi.org/10.1016/j.phymed.2020.153287.

37. Fugh-Berman, A. Herb-drug interactions. The Lancet 2000, 355, 134-138, https://doi.org/10.1016/S01406736(99)06457-0.

38. Shu-feng, Z.; Zhi-wei, Z.; Chun-guang, L.; Xiao, C.; Xiyong, Y.; Charlie, C. Identification of drugs that interact with herbs in drug development. Drug disc today 2007, 12, 664-673, https://doi.org/10.1016/j.drudis.2007.06.004. 
39. Zhon, S.; Palmeira, C.M.; Wallace, K.B. Doxorubicin-induced persistent oxidative stress to cardiac myocytes. Toxicol Lett 2001, 121, 151-157, https://doi.org/10.1016/s0378-4274(01)00329-0.

40. Lenaz, L.; Page, J. Cardiotoxicity of Adriamycin and related anthracyclines. Cancer Treat Rev 1976, 3, 111120, https://doi.org/10.1016/S0305-7372(76)80018-7.

41. Myers, C.F.; McGuire, W.P.; Liss, R.H. Adriamycin: The role of lipid peroxidation in cardiac toxicity and tumor response. Sci 1977, 197, 165-67, https://doi.org/10.1126/science.877547.

42. Bier, C.C.; Jaenke, R.S. Function of myocardial mitochondria in the Adriamycin induced cardiomyopathy of rabbits, J Natl Cancer Inst 1976, 57, 1091-1094, https://doi.org/10.1093/jnci/57.5.1091. 